\title{
Innovative potential of a teacher in a new reality: challenge and response
}

\author{
Yulya Selezneva ${ }^{*}, 1$ \\ ${ }^{1}$ Don State Technical University, 344003, 1, Gagarin sq., Rostov on Don, Russia
}

\begin{abstract}
The article deals with the problem of the professional development of a teacher in the new educational reality and the conditions that ensure the effectiveness of his professional work. Modern challenges (among which the challenge of uncertainty occupies a special place) determines and defines the innovative way of development of education and the teacher today. The innovative potential is considered as a systemforming component in the structure of the teacher's professionalism; features in the development of innovative potential are described using the example of preschool educational institutions and the risks of the management system in ensuring the effectiveness of professional activity are analyzed. Key words: innovation, innovation potential, sense formation, vitality, responsibility, reflection, professional deformation.
\end{abstract}

\section{Introduction}

Turning to the modern socio-cultural situation allows us to describe the characteristic acceleration of the pace of life, the catastrophically rapid development of global world processes: unpredictability of social events increases, and at the same time, the need to find ways of scientific prediction and control of them becomes more and more insistent; to find new methods of solving problems that would correspond to the complexity of the modern situation, were oriented towards action in conditions of high uncertainty, would remove the disruption of the world and alienation of people. Undoubtedly, the uncertainty of the World, which requires a teacher to restructure his thinking, habitual methods of action, becomes a stress factor for a significant part of teachers, but at the same time is a powerful source of development. Being associated with a special cognitive practice, it is the situation of uncertainty that allows, in the absence of specified algorithms, to experience a new experience, to rethink reality, to form a new culture of experiences through an emotional attitude to phenomena and objects of reality, and on this basis to structure a new picture of the World. We can say that this is a new way of making sense today, which largely ensures decision-making by a subject in a difficult new reality.

Analyzing the challenges of our time, of course, the challenges of the information world should also be noted. The information flows that have literally hit a person over the past decades have significantly rebuilt the system of interpersonal connections, influenced the nature of mental processes of a growing Person, defining new possibilities for the

\footnotetext{
*Corresponding author: yulya.selezneva@gmail.com
} 
perception and processing of information, thinking, self-awareness and emotional-volitional regulation. A modern child and his new values, a new look at the World and a type of behavior that is not always clear to us, perception of phenomena and events, a new structure of thinking and the ability to build his own strategies of behavior already from preschool age - at one pole; on the other, the teacher often misunderstands the global changes of modern childhood; generation gap and the complexity of communication of all subjects of the educational space. Moreover, the changes affected not only the teacher-child relationship, but also communication in the Parent-Teacher-Child system, which significantly changed the position of the teacher in the educational field. Indeed, today even the educational trajectory of a child, his development prospects are not only in the hands of the state and the educational system, but to no less extent is the prerogative of the family. And this incredible openness of education today gives a powerful impetus to the development of the educational system as a whole, significantly restructures the position of the teacher within the educational situation, transforms the interaction of all subjects of the educational process.

Thus, the time of global Challenges is also the Time of Opportunities - it is another coordinate system, which is being established "here and now" and changes the fundamental lines of organizing the teacher's professional activity.

However, what conditions can facilitate the disclosure of these opportunities? What determines the innovative path of education development today? What resources should a management system have, which sets the individual trajectories of professional development of subjects of labor and ensures the effectiveness of pedagogical activity?

The recent experience of the pandemic (as in a mirror) showed our capabilities and our objective professional result; further exacerbated the polarization among teachers. Under the conditions of an unfamiliar environment, new requirements (for which no one was ready), a significant part of teachers nevertheless strove to rethink and adapt the new situation to the current process, and in general was ready for the volatility of the World; teachers turned out to be more stress-resistant, ready to take risks and accept responsibility. And, unconditionally, they showed the ability to act. And those technologies that turned out to be in demand in the new environment - acted as a resource for the development of education and at the same time the teacher himself. The innovative potential that a significant part of teachers has or is developing helped to cope with situations of uncertainty and find the necessary ways to organize work, and the teacher's special abilities to carry out innovative activities (which will be discussed below) made it possible to bring the situation to the point of effectiveness. After mastering and introducing new technologies, we cannot always accurately predict the result. And therefore, competencies that allow timely measurement and tracking of changes at all stages of innovation have become significant in the new educational reality.

Undoubtedly, the challenge of uncertainty is the most significant today. And this is not only a question of finding solutions and answers, but also an opportunity to assess the effectiveness of one's activities, to rethink the existing experience, to see new meanings of work; globally - an opportunity to make a choice and take responsibility for one's actions. Returning to the situation of the pandemic, it should be noted that each of us had such an understanding: we saw our achievements through the activity of children, their motivation, the productivity of our joint new experience. Was each teacher able to refer to these observations, how did this experience influence the organization of a new teaching format, what percentage of teachers were able to act in a new situation and be effective?

In this sense, the concept of "intellectually and personally-mediated choices in a situation of uncertainty" is interesting of T.V. Kornilova. The author, considering the functional-level regulation of the decision-making process, in addition to the intellectual, identifies such components of personal regulation as the activity of the subject in building 
an image of a situation of choice, acceptance of responsibility and risk in a situation of uncertainty. Developing a theory within the framework of the cognitive direction, T.V. Kornilova emphasizes that regulation in this case is carried out not only at the intellectual level, but necessarily including semantic and personal regulation; "A situation of inner personal effort." [9]

Thus, the challenges of our time are primarily existential challenges; covering the issues of free will, "determination to Be", responsibility. Moreover, speaking of responsibility, it is interesting to follow E.D. Dorofeev to consider in relation to this problem such a vector of responsibility as "individual responsibility for an increasing number of people." We are responsible for group norms (the result of our past interactions); for the desire to change norms, for the real state of the group. Thus, the three-dimensional model of group responsibility (past, present, future) by E.D. Dorofeev includes, along with the characteristics of relationships in a group, the characteristics of the subject himself (as a subject capable of taking responsibility for himself and for changing the group as a result of his actions). And this important moment was once noted by V.A. Ivannikov as a criterion of personality. It is the ability to make a Choice, taking into account the consequences "for Others equal to themselves" and the acceptance of responsibility for their own decisions, in the author's opinion, characterizes a Man as a person. Awareness and decision-making in a situation of Choice, taking responsibility for the consequences of one's decisions, committing an act and, finally, Choosing one's way of Life makes up a picture of the Personality and subsequently leads to the formulation of a task that is possible only for a Human - the task of changing oneself. By accepting the Choice, we find ourselves in a new relationship with the World and with ourselves.

Thus, we are at the point where the problem of mastering and introducing innovations is not so much a question about technologies and new ways of interacting with the environment, but rather a question about the teacher's personal resource, "keeping the effort in time" (M.K. Mamardashvili) and ensuring transition of education to a new level of development.

It would be appropriate to compare the current situation of the development of education with the civilizational approach of A. Toynbee in his concept of the development of civilizations. "A person reaches civilization not as a result of biological talent (heredity) or light conditions of the geographical environment, but in response to a challenge in a situation of special difficulty, inspiring him to an unprecedented effort." Nature throws down a challenge to people and with its response, civilization solves the task before it and transfers itself to a more perfect state. And the stronger the challenge, the more original and creative is the response. It can be assumed that education, experiencing a kind of crisis today, is at a point where incentives can stimulate an adequate "response" and from how we understand the nature of the phenomena occurring, mechanisms of new teacher behavior are built, which are also rebuilding the education system. The challenges of our time, although complex, however, stimulate the disclosure of new Human resources, providing innovative behavior as a natural and logical way of education development.

For a long time we talked about innovations, about an innovative personality type, about readiness for innovative activities; developed projects and programs to support the teacher's innovative activity, assuming that he can choose whether to be included in the innovative mode or carry out professional activities in the traditional mode. The present situation seems to be characterized by a lack of choice. The world and educational practice have changed so much that a teacher can hardly be effective and successful outside of innovative behavior. Thus, innovative transformations, on the one hand, act as a logical and timely response to social changes in society (as the need to solve super-tasks, in particular in educational practice), on the other hand, inclusion in innovative activities is largely due to the natural essence of man as a subject of activities. 
And so, innovative education does not translate, but rather generates new experiences; it is not always focused on solving the problem "here and now", but to a greater extent on creating cognitive gaps (sensitivity to problems is great) and understanding new layers of social reality, educational practice. And just the factor of misunderstanding is extremely important in the formulation of problems that need to be solved. Because of this, one of the most powerful factors in the development of education is the teacher himself: his ability to think and function divergently in a situation of uncertainty; be stress-resistant and receptive to new things, emotionally feel the World and be able to creatively transform it. At the same time, it is important to note that the above indicators of innovative activity by themselves do not provide innovative behavior. Innovative behavior as a form of human activity, which is carried out by going beyond the established attitudes and behavioral stereotypes, arises at those points of a person's living space where three factors converge: a person's capabilities, represented by his personal, spiritual, creative, intellectual potential; an environment that meets these opportunities; a person's readiness to realize his capabilities "here and now". Thus, innovation as a system is characterized by the presence of integral systemic qualities generated by the communication space - innovative opportunity, innovative ability, innovative potential. (G.I. Gerasimov)

In the system of personal qualities, indicating the innovative potential of a person, the most defining factors are the willingness to change, the need for risk, the ability to act in conditions of insufficient information, leadership qualities of an individual (M. Woodcock and D. Francis); curiosity; preservation of juvenility, childishness in behavior and attitude to the world; perfectionism as a striving for accuracy and perfection in actions performed, a sense of humor, as a phenomenon positively correlated with intelligence), social autonomy as a willingness to act independently, regardless of the support of others. (A. Savenkov)

Thus, innovative potential always includes a personal component, along with communicative, intellectual, creative and general abilities for innovation. And in fact, in the present situation, the personal resource is the most important component in the structure of the teacher's innovative behavior. Summarizing the above-mentioned characteristics of the personal component of the innovative potential, one should single out such a concept as resilience (C.Maddy), which includes three parameters: involvement in what is happening as an opportunity to emotionally and intellectually be involved in events; control as autonomy and responsibility; willingness to take risks - understanding and accepting life as a way of experiencing a variety of (positive and negative) experiences.

Indeed, a teacher who is truly involved in professional activities, is more capable of intellectual and emotional assessment of the situation, is more sensitive to problems in teaching practice; ready and able to control current changes, which allows him to be autonomous and be responsible for what happens to him and in the World.

Thus, the structure of innovation potential, in our opinion, includes a certain personal resource, represented by such categories as resilience, self-acceptance in the profession and positive self-attitude; responsibility; pedagogical flexibility and creativity of the teacher as a general ability for creativity (independence of judgment, intellectual ease in dealing with ideas, lack of stereotypes, sensitivity to problems, critical thinking, ability to value judgments, ability to reflect); and, finally, special abilities to carry out innovative activities (ability to accumulate and use the experience of creative activities of other teachers, ability to create an author's concept, ability to plan and analyze own activities, etc.).

\section{Methods}

Within the framework of "Monitoring the quality of professional activities of preschool educational institutions", we carried out a study that includes, along with an assessment of professional competence study of the teacher's ability and readiness for innovative 
activities. Within the framework of this article, I would like to comment on some of the results.

In order to study the teacher's readiness for innovative activities, we used the "Map of the pedagogical assessment of the teacher's abilities for innovative activities" (V.A. Slastenin, L.S. Podymova). This technique allows to identify the creative potential of a teacher and record the following indicators of his readiness for innovative activities:

- Motivational and creative orientation of personality (personal significance of creative activity, curiosity, creative interest);

- Teacher's creativity (independence of judgment, intellectual ease in dealing with ideas, lack of stereotypes, sensitivity to problems, critical thinking, ability to value judgments, ability to reflect);

- Assessment of professional abilities to implement innovative activities (ability to accumulate and use the experience of creative activities of other teachers, ability to create an author's concept, ability to plan own activities, etc.);

- Individual characteristics of the teacher's personality (pace of activity, responsibility and self-confidence, conviction in the social significance of creative activity, ability to selforganize).

Considering the ability to innovate as the simultaneous representation of the motivational component in innovation, creativity, specific abilities to carry out innovative activities, as well as the presence of certain personal qualities that allow to act effectively in an innovative mode, within the framework of monitoring, analysis of data for each of the presented parameters presents a special interest.

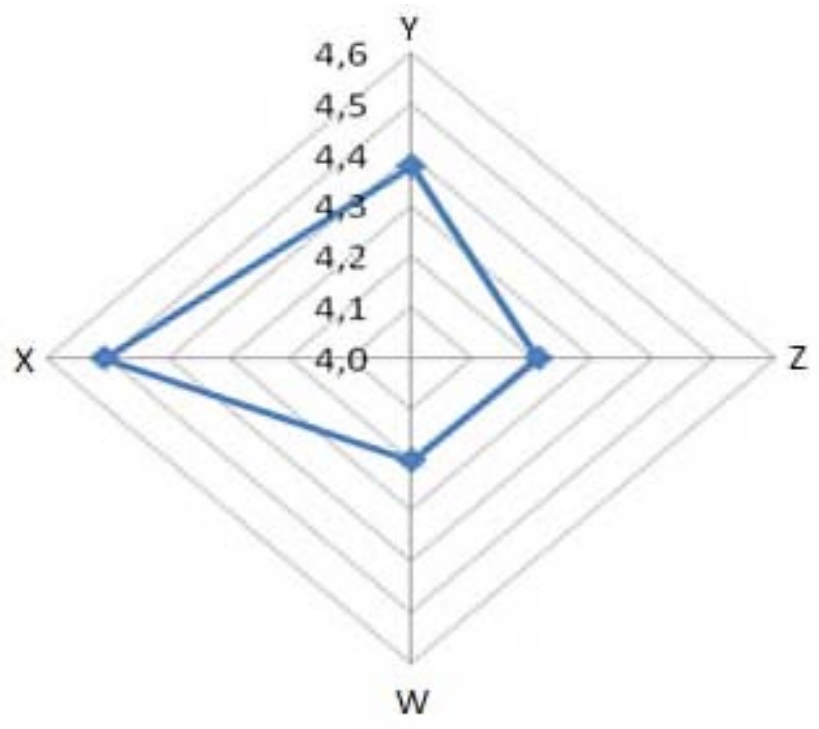

Fig. 1. Average values in the study of the teacher's ability to innovate.

where «Y» is motivational and creative focus; " $\mathrm{Z}$ " is creativity; " $\mathrm{W} "$ is the teacher's ability to carry out innovative activities; " $\mathrm{X}$ " is individual personality traits.

\section{Results and discussion}

Thus, 54\% of the surveyed respondents had a high degree of motivational readiness to carry out innovative activities: teachers show curiosity, creative interest, emphasize the personal significance of creative activity. It is important to note that mastering special professional 
skills in combination with a high level of motivational readiness provide good results of innovative activities. And on the contrary, formed professional skills and lack of motivation, negative attitude to their profession, low susceptibility to innovations can significantly affect the effectiveness of the activities being carried out. However, it should be noted that only $32 \%$ of the monitoring participants had high indicators in relation to the study of special abilities to carry out innovative activities: possession of methods of pedagogical research, the ability to plan and set goals for experimental work, the ability to organize a pedagogical experiment, to track its effectiveness. In fact, the so-called metacompetencies, which ensure the overall effectiveness of the teacher's activities, are extremely significant in the organization of innovative activities. It is the special abilities for planning, analyzing, and reflecting on the results that provide a balanced approach to the selection of innovations, a qualitative assessment of the effectiveness at all stages of the introduction of innovations, goal-setting as the setting of intermediate private goals and the selection of the necessary tools for achieving goals. The greatest number of low values was noted on the "Creativity" scale. In a broad sense, "creativity" is a person's creative abilities, reflecting a certain sensitivity to problems, flexibility and ease in dealing with ideas, the ability to develop own hypotheses, a sufficient level of development of reflection, ensuring the variability of pedagogical activity. In our opinion, taking into account the identified deficiencies in the innovative potential of a teacher in the educational environment of educational institutions will contribute to the formation of the innovative readiness of teachers to work in an innovative mode and increase the efficiency of professional activity.

Currently, the coverage of teachers included in the innovation regime is quite large. Involved in innovative transformations with varying degrees of readiness, teachers can not only create risks for the educational system in the sense of low effectiveness of pedagogical work, but also the issues of preserving the professional health of a teacher become relevant. The need to introduce innovations without sufficient readiness can provoke the development of various professional destructions in the teacher and act as additional stress.

As an example, we cited the concept of A. Toynbee to illustrate the current situation in education. The challenge-response concept provides a key to understanding the creative nature and possible cultural transformation. The development of culture is carried out as a series of responses given by the creative human spirit to the Challenges that nature, society and the inner infinity of man himself throws at him, which seems completely natural in the dynamics of culture, thereby marking a period of qualitative changes, socio-cultural transformations $[19,21]$. At the same time, various options for development are always possible, because different Answers to the same Challenge are possible.

\section{Conclusions}

In conclusion, I would like to note the following.

We are getting faster, but it is more and more difficult for us to stop and reflect.

We become more flexible, but we lose stability.

We value and plan time, but spontaneity and the ability to observe what is happening disappear from life, which provides a clearer perception and vision of the Picture of the World...

We strive to be more productive, but we lose the meaning of real productive action, which, according to P. Shchedrovitskiy, always takes into account the Other, being born in "joint thought activity", is built on the experience of reflection and allows saving the resource of Time.

We strive to fill the void, but we often forget that it is losses that give rise to real meanings. 


\section{References}

1. A. G. Asmolov, E. D. Shekhter, A. M. Chernorizov, Preadaptation to uncertainty as a strategy for navigating developing systems: evolution routes. Psychology, 4, 3-26 (2017)

2. A. L. Caruso, Burnout experience among teachers: a case study. Mediterranean Journal of Clinical Psychology MJCP, (2)3 (2014)

3. O. Clipa, A. Boghean, Stress factors and solutions for the phenomenon of burnout of preschool tearchers. The 6th International Conference Edu World «Education Facing Contemporary World Issues» (2014)

4. O. Clipa, A. Ignat. Teachers satisfaction with life, job satisfaction and their emotional intelligence Procedia Social and Behavioral Sciences, Elsevier-Science Direct, 33, 498-502 (2012)

5. E. F. Zeer, E. A. Yugova, N. P. Karpova, O. V. Trubetskaya, Psychological predictors of human hardiness formation. International Journal of Environmental and Science Education (2016)

6. M.K. Mamardashvili, Conversations about thinking. ABC, St. Petersburg (2018)

7. G. Masari, D. Muntele, V. Curelariu, Motivation, work-stress and somatic symptoms of Romanian preschool and primary school teachers, Procedia - Social and Behavioral Sciences, 84, 332-335, 25-34 (2013)

8. D. A. Leontiev, Man and world of life: from ontology to phenomenology/ Cultural historical psychology, 15(1) (2019) doi 10.17759/chp.2019150103

9. D. A. Leontiev, E. Y. Ovchinnikova, E. I. Rasskazova, A. Kh. Fam, Psychology of Choice (Meaning, Moscow, 2019)

10. V. A. Petrovsky, Man over the situation, Smysl, Moscow (2010)

11. V. R. Preda, Stress effects and copiing strategies for teachers and pupils http://doctorat.ubbcluj.ro/sustinerea_publica/rezumate/2010/stiinte $\% 20$ ale $\% 20$ educatie i/ Preda_Vasile_Radu_ro.pdf (Last accessed 11.05.2020) (2010)

12. E. E. Symanyuk, I. V. Deviatoskaja, Life-long education as a resource to overcome the psychological barriers in the process of professional development of the individual. The Education and science journal, 1(1), 80-92 ISSN 2227-7102 (2015)

13. T. Shcherbakova, E. Alimova, The psychosemantic readiness of a teacher for effective communication in a multicultural educational environment, Rostov-on-Don (2016)

14. B. W. Swider, R. D. Zimmermann, Born to Burnout: a meta analytic path model of personality, job Burnout and work outcomes. Journal of Vocational Behavior, 76, 487506 (2010)

15. L. E. Sandilos, P. Goble, S. E. Rimm-Kaufman, R. Pianta, Does professional development reduce the influence of teacher stress on teacher-child interactions in prekindergarten classrooms? Early Childhood Research Quarterly, 42, 280-290 (2018) 